\title{
Juridisk literacy i skolen. Ikke-juristers lovtekstlesing og rettsanvendelse
}

\author{
Henning Fjørtoft, Gunhild Åm Vatn and Pia Farstad Eriksen \\ Henning Fjortoft: Institutt for lererutdanning, NTNU, Trondheim, Gunhild Am Vatn: \\ Institutt for språk og litteratur, NTNU, Trondheim Pia Farstad Eriksen: Institutt for språk \\ og litteratur, NTNU, Trondheim
}

\begin{abstract}
Lovtekster regulerer viktige samfunnsområder, og anvendes som verktøy for å utøve skjønn og ta avgjørelser i ulike virksomheter. Artikkelen undersøker hvordan opplæringslova (lov om grunnskolen og den vidaregåande opplæringa) forstås og anvendes i hverdagen av henholdsvis skoleledere, foreldrerepresentanter ved en norsk ungdomsskole og skolefaglige ansatte i samme kommune. Gjennom gruppeintervjuer med høyttenkningsmetode undersøkes deltakernes erfaringer med bruk av lovtekstene, lesestrategier og refleksjoner over selve leseprosessen. Studien finner at lesere med lav kjennskap til juridiske tekster primært anvender sosiale strategier for å forstå: De spør om hjelp i sin profesjonelle eller private omgangskrets. Bare unntaksvis anvender de tekstbaserte strategier (lesing av andre rettskilder). Ikke-jurister er derfor avhengige av veiledning for å håndtere juridiske problemstillinger. Slik støtte er imidlertid ujevnt fordelt geografisk og befolkningsmessig. Et annet funn er at de intervjuede opplever en økende rettsliggiøring, og at dette fører til en ny bevissthet om juridiske spørsmål.
\end{abstract}

Nøkkelord: Lovtekster; tolkningsfellesskap; forvaltning; leseforståelse; lesing $i$ arbeidslivet

\begin{abstract}
Legal texts regulate key aspects of society, and are used as tools for exercising discretion and decision-making in various professional contexts. This paper investigates how the Norwegian Education Act is understood and applied in everyday contexts by school leaders and parent representatives at a Norwegian lower secondary school, as well as school administrators at the municipality level. Through group interviews and using a think-aloud procedure, participants' experiences and use of legal texts, reading strategies, and reflections on reading legal texts are explored. The study finds that readers with little knowledge of legal texts primarily use social strategies to comprehend the text; they ask for help in their immediate personal and professional networks. Only rarely do they employ text-based strategies (reading other legal sources). As laypersons, they therefore rely on support and guidance in order to solve legal problems. Such support, however, is unevenly distributed in the population. Furthermore, the interviewees' experience was that the educational system is characterized by an increasing reliance on legal procedures, leading to a heightened consciousness for legal questions.
\end{abstract}

${ }^{\star}$ Correspondence to: Henning Fjørtoft, Institutt for lærerutdanning, Fakultet for samfunns- og utdanningsvitenskap, NTNU, 7491 Trondheim. Epost: henning.fjortoft@ntnu.no 


\section{H. Fjørtoft et al.}

Keywords: Legal texts; interpretive community; public administration; reading comprehension; workplace reading skills

Received: February, 2017; Accepted: September, 2017; Published: November, 2017;

Lover og regler griper inn i stadig større områder av samfunnsborgeres liv. En slik rettsliggjøring kan innebære at jurister får større betydning når individers eller gruppers rettigheter skal forsvares (NOU 2003: 19). I offentlig forvaltning foregår imidlertid rettsanvendelse ofte ved at ikke-jurister treffer mange avgjørelser på kort tid uten den tid til grundig behandling som karakteriserer domstolene (Eckhoff \& Helgesen, 2001, s. 17). Studier av ikke-juristers lovtekstforståelse og rettsanvendelse kan bidra til dypere forståelse for hvordan ulike forvaltningsinstanser ivaretar borgeres rettigheter. Det finnes imidlertid få empiriske undersøkelser av ikke-juristers rettsanvendelse og lesing av lovtekster (Nord, 2011; se Andenæs \& Møller (2016) og Gunnarsson (1982) for unntak fra dette).

God saksbehandling og tillit til forvaltningens rettsanvendelse og profesjonelle skjønn er spesielt viktig i skolen, der rettighetene til elever fra ulike sosiale lag skal ivaretas. Lover og læreplaner fastsetter rammer og rettigheter og definerer dermed det prinsipielle handlingsrommet som det profesjonelle skjønnet skal utøves innenfor (Herlofsen \& Nilsen, 2016). I slike sammenhenger innebærer skjønnsutøvelse at profesjonsutøvere vurderer den enkelte situasjon på selvstendig grunnlag ut fra sin forståelse for rettslige og fagspesifikke forhold, grovt kategorisert som «samlebåndssaker» der jussen er relativt klar (f.eks. skolebytte, skoleskyss og standpunktkarakterer) og mer komplekse saker der mange ulike hensyn må tas (f.eks. elevenes rett til et godt psykososialt miljø eller til spesialundervisning) (Welstad, 2011). I praksis er imidlertid juridisk ekspertise sjelden tilgjengelig på den enkelte skole. Skoleledere og andre som skal ta avgjørelser på rettslig grunnlag, må derfor basere seg på skjønnsutøvelse ut fra de rettskilder og den juridiske kunnskap de har tilgang til.

Denne studien springer ut fra et prosjekt om forståelsen av lovspråk i det offentlige, som var en del av satsningen «Klart lovspråk» (se Direktoratet for forvaltning og IKT, 2017; Vatn, Eriksen, \& Fjørtoft, 2015). Vi utforsker hvordan foreldre, skoleledere og skoleeierrepresentanter i grunnskolen forstår og anvender opplæringslova for å løse problemer i sin kontekst. Gjennom å beskrive deltakernes levde erfaringer med lesing av lovtekster søker studien å undersøke de strategier som anvendes for å forstå loven, ta avgjørelser og håndtere konflikter. Først diskuterer vi begrepet juridisk literacy som utgangspunkt for å undersøke hvordan lovverket leses og anvendes av de ulike aktørene. Deretter presenterer vi metodologiske perspektiver på studier av juridisk literacy i skolen. Til slutt diskuterer vi tre dimensjoner av juridisk literacy som er spesielt relevante i skolesammenheng: strategier for problemløsning, tolkningsfellesskap og økende rettsliggjøring.

\section{Juridisk literacy}

Profesjoners kunnskapsområder er nært knyttet til akademisk literacy, forstått som spesifikke former for tekstkompetanse og utviklingen av institusjonaliserte sjangre 
og tenkemåter (Geisler, 1994). Termen juridisk literacy anvendes både om lesing av lovtekster som individuell aktivitet og om deltakelse i et spesialisert tekstfellesskap (Bell \& Pether, 1998; Schimmel \& Militello, 2007). Å lære å håndtere juridiske problemstillinger kan derfor på den ene siden forstås som en kognitiv prosess der man tilegner seg forståelse for et sett med språklige ressurser og symbolske verktøy (Bazerman, 1997), og på den andre siden som en sosialisering inn i de diskurser og verdier som kjennetegner en gruppe (Gee, 2012, s. 163).

Sentralt i juridisk literacy står kunnskap om ulike rettskilder og deres relevans i juridisk argumentasjon. Når jurister skal besvare et rettsspørsmål, anvender de juridisk metode (også kalt rettskildelære), som basert på rettspraksis og juridisk teori trekker rammer for hva som kan anses som rettslig gyldige eller ugyldige argumenter, og hvilken vekt argumentene skal tillegges. Kunnskap om rettskildelære innebærer å kunne resonnere om hvordan retten er (de lege lata), og å kunne skille dette fra synspunkter om hvordan retten burde vare (de lege ferenda) (Eckhoff \& Helgesen, 2001, s. 15). Også ikke-jurister kan tilegne seg forståelse for juridiske tekster og problemstillinger. Juridisk literacy kan derfor forstås som et spektrum fra grunnleggende kunnskap om juridiske ord og uttrykksformer på lavt nivå, til full deltakelse i juridiske diskurser som leser og skriver (White, 1982).

Lovtekster inneholder ulike former for vaghet og flertydighet, og jurister må avklare hvordan rettskildebildet avgrenser tolkningsrommet (Kolflaath, 2004). Betegnelsen «lovtolking» er en sammensatt virksomhet, og juridiske standpunkter bygger på språklig analyse av tekster, hypoteser om hva lovgivere har ment, vurderinger av hvilket innhold regelen bør ha og hvordan en gitt sak bør avgjøres, kunnskaper om tidligere praktisering av bestemmelsen i domstolene og lignende (Eckhoff \& Helgesen, 2001, s. 35-36). Tolkning i jussen innebærer altså ikke bare å trekke slutninger og skape mening $\mathrm{i}$ tekst i generell forstand, men mer konkret å anvende juridisk metode for å treffe avgjørelser. Lesing av lovtekster er derfor et godt eksempel på en disiplinær eller fagspesifikk literacy (Shanahan, Shanahan, \& Misischia, 2011) der kunnskap om og anvendelse av juridisk metode står sentralt.

Jusstudenter utvikler sin juridiske literacy fra en begynnerfase der de prioriterer å huske og forstå innholdet i lærebøkene til senere å anvende en kombinasjon av kilder som for eksempel lover, domsavsigelser og egne erfaringer. Å mestre juridisk metode $i$ tolkningen av lovtekster og utformingen av rettslige argumenter er en sentral del av den fagspesifikke lese- og skrivekompetansen som jurister tilegner seg gjennom utdanning og erfaring (Strømsø, 2003). Hos ikke-jurister utvikles juridisk kompetanse derimot mer usystematisk giennom levde erfaringer. Rettsantropologiske studier har vist at enkeltmenneskers juridiske bevissthet dannes i møte med embetspersoners og moderne byråkratiers tekstpraksiser, at de opplever juss både som et abstrakt regelsystem og som en materiell virkelighet, og at slike erfaringer gjerne manifesterer seg $i$ et narrativt format som fortellinger om slike møter (Cover, 1992; Ewick \& Silbey, 1998). Allmenne borgere mangler dessuten ofte kunnskap om sine juridiske rettigheter, noe som kan få negative konsekvenser for sårbare eller rettsfjerne individer (Papendorf, 2012). Mens jurister forstår juridiske problemstillinger ut fra teorier og 


\section{H. Fjørtoft et al.}

teknikker som er utviklet gjennom profesjonens historie, vil altså lekpersoner ofte tolke problemer ut fra sine umiddelbare behov som borgere (Barnes, 2006).

Betegnelser som «allmenne borgere» og «ikke-jurister» er imidlertid svært generelle. Ifølge Nord (2011) hviler offentlig språkbruk på mer eller mindre velfunderte antakelser om hva gjennomsnittslesere behøver eller hva som generelt gjør tekster leservennlige. Justisdepartementet anbefaler for eksempel at lovtekster bør ta rettspedagogiske hensyn for å «sikre at regelverket når best mulig frem til dem som det angår» (Justis- og politidepartementet, 2000, s. 22). Det antas at vanlige brukere ikke har tilgang til andre rettskilder enn selve lovteksten, og at utfyllende merknader, begrepsavklaringer og annen fortolkningsstøtte som finnes i lovforarbeidene, bare er tilgjengelig for fagpersonale (Justis- og politidepartementet, 2000, s. 25-26). Dette ser en blant annet i den digitale utgaven av Lovdata. Nettstedet skiller mellom en gratisversjon for vanlige brukere og en betalingsversjon for profesjonelle, som inneholder et større utvalg lovforarbeider, rettsavgjørelser, vedtak, uttalelser, juridiske artikler, internasionale rettskilder samt kommentarer til rettskildene. Justisdepartementet skiller imidlertid bare grovt mellom allmenheten og fagpersoner og bekrefter dermed Nords (2011) påstand om orienteringen mot en gjennomsnittsleser.

Studier av ikke-jurister som rettsanvendere har vist at de vektlegger andre argumenter og hensyn enn de tradisjonelt rettslige når saker skal avgjøres. For eksempel kan ikke-jurister bruke økonomiske, organisatoriske eller moralske og verdimessige argumenter når de tar avgjørelser; rettsreglene spiller i slike tilfeller en mindre rolle, noe som kan skyldes mangelfulle kunnskaper om juss, «ujuridiske» holdninger samt manglende tilgang på hjelpemidler (Andenæs \& Olsen, 1990, s. 103). Videre kan skoleledere og andre ikke-jurister oppfatte rundskriv og veiledere som mer autorative enn det rettskildelæren legger til grunn (Welstad, 2011). Nord (2011) understreker behovet for «fler studier av hur myndighetstexter faktisk blir lästa eller använda» (s. 24).

Forsøk på å styre praksis i skolen med rettslige mekanismer kan være utfordrende siden det juridiske tolkningsfellesskapet er relativt svakt i skolen. Sandvik et al. (2012) undersøkte for eksempel hvordan endringer i vurderingsforskriften til opplæringslova ble forstått av ulike aktører, og de fant sprikende forståelse og implementering, noe som i sin tur får konsekvenser for elevens læring. Andre har vist at skoler bruker standardiserte tekstmaler i kommunikasjon med hjemmet for å ivareta det juridiske grunnlaget for enkeltvedtak; dette kan føre til at tekstene er vanskelige å lese, noe som svekker de foresattes forståelse av skolens vedtak og som hindrer deltakelse i kommunikasjonen mellom skole og familie (Halstensgaard, 2016). Også følelsesmessige dimensjoner spiller en rolle: Schimmel og Militello (2007), som har undersøkt amerikanske læreres juridiske literacy, påpeker at lærere ser på loven som en kilde til frykt og engstelse, og at de er redde for å gjøre uskyldige feil med potensielt store konsekvenser. Juridisk literacy bør derfor forstås som et bredt felt som dekker både individuelle juridiske kunnskaper og ferdigheter, levde erfaringer, normer og personlige tanker og følelser knyttet til problemstillinger som loven regulerer. 


\section{Metode og datagrunnlag}

Å forske på juridisk literacy

Vår studie anlegger et kvalitativt perspektiv på ikke-juristers lovtekstlesing og rettsanvendelse. I rettssosiologien utgjør kvalitative metoder et viktig komplement til domsanalyser fordi de tilbyr innsikt i dynamikken mellom idealer og realiteter i profesjonsroller (Lundeberg, 2009). Skjønnsutøvelse innebærer for eksempel å måtte ta stilling til innbyrdes motstridende normer. Leo (2010) viser at rektorer i skolen styres både av rettslig regulerte normer og profesjonelle normer (sosialt definerte normer som er skapt i et profesjonelt system, og som angir hvilke handlinger som er forventet av en yrkesutøver); skolelederne forteller at dialog er et sentralt virkemiddel for å omsette tanker til handlinger, og at de ofte opplever et sterkt krysspress i sin rolle. I skjønnssituasjoner kan det for eksempel oppstå konflikter mellom det juridiske språket som anvendes i styringsdokumenter og de praktiske behovene for å kommunisere klart med ulike befolkningsgrupper. Det juridiske skillet mellom spesial-undervisning og tilpasset opplaring er et eksempel på begrep som kan utløse konflikter. Papendorf (2012) påpeker at reglene for spesialundervisning har stort rom for profesjonelt skjønn. Utviklingen innenfor dette juridiske området har ledet til en "spesialiserings- og kompleksitetstilvekst som medfører at ikke-juridiske profesjoners stemme i rettsanvendelsen har blitt en viktig faktor for rettsutfallet» (s. 196). Kvalitative studier kan derfor gi innsikt i erfaringene til mennesker som berøres av rettslig regulering i skolesammenheng.

Lesing i jobbsammenheng arter seg ofte som en samarbeidsprosess der enkeltmennesker kombinerer sitt personlige repertoar av kunnskaper og strategier med sosiale interaksjonsformer som å søke i databaser, stille spørsmål til kontakter og å bruke sitt nettverk for å skape mening og løse problemer (Evans, Kairam \& Pirolli, 2010). Forskning på erfarne leseres forstålse og strategier har imidlertid primært anvendt laboratoriebaserte forskningsmetoder, noe som kan ha ført til atypiske leseprosesser hos deltakerne (Bråten \& Strømsø, 2003). Studier av kommunikasjon på arbeidsplasser har derfor problematisert individorienterte metodologier fordi praktisk problemløsning gjerne skjer i samarbeid der den situerte forståelsen av teknologi og informasjon står sentralt (Luff, Heath, \& Hindmarsh, 2000). Et slikt perspektiv innebærer å flytte oppmerksomheten bort fra leseres individuelle kognisjon og over til en lokalt situert og målrettet sosial aktivitet der tekster og andre verktøy inngår $\mathrm{i}$ interaksjonen mellom ulike lesere (Beach, 2000). Vi valgte derfor å studere sosiale prosesser der lesing av lovtekster inngår. Intensjonen med en slik metodisk inngang var å samle empiriske data knyttet til selve tekstlesingen, til deltakernes personlige erfaringer med rettsanvendelse, og til følelser og normer hos deltakerne.

\section{Datainnsamling}

Siden det kunne være stor lokal variasjon i deltakernes levde erfaringer og virksomhetsrutiner, valgte vi en utforskende tilnærming. Vi innhentet godkjenning fra NSD og inviterte tre grupper aktører til gruppeintervjuer: tre skoleledere (rektor og to 


\section{H. Fjørtoft et al.}

mellomledere) ved en ungdomsskole $\mathrm{i}$ en større norsk by, tre foreldrerepresentanter ved skolens foreldrearbeidsutvalg (FAU) og tre ansatte på kommunenivå som arbeidet med regelverk for skole og oppvekst (en jurist og to rådgivere uten juridisk utdanning). Skolelederne som ble forespurt, var et bekvemmelighetsutvalg. Skolen rekrutterer elever fra variert sosioøkonomisk og etnisk bakgrunn.

For å sikre triangulering i datagrunnlaget valgte vi et tredelt intervjudesign. Først stilte vi spørsmål til deltakerne om deres generelle erfaringer og bakgrunnskunnskaper om loven. Eksempel på spørsmål er «Hvordan opplever dere å finne frem i lovteksten?» og «Hva gjør dere hvis dere er usikre på hva lovteksten betyr?» Deretter fikk de en høyttenkningsoppgave der de leste teksten og tenkte høyt om sin egen tenkning. Høyttenkningsmetoder (verbal protocols) defineres som en aktivitet der «subjects report their thinking as they do a task» (Pressley \& Afflerbach, 1995, s. 1). Deltakerne ble bedt om å lese halvannen side med utvalgte paragrafer fra opplæringslova på totalt 395 ord ( $\$ \mathbb{S} 1-3,5-1,8-2,9 a-3)$. Vi valgte paragrafer som vi antok ville være spesielt utfordrende problemfelt i skolen, men forventet at deltakerne hadde varierende erfaring med den konkrete teksten. Til slutt initierte vi en metadiskusjon der deltakerne fikk kommentere selve intervjusituasjonen. Tredelingen gjorde det mulig å skille mellom erfaringer med lovtekstens virkeområde, strategisk lesing og fortolkning av lovteksten og refleksjoner over selve intervjusituasjonen.

Kvalitative studier der høyttenkningsoppgaver inngår, kan kaste lys på faglig problemløsning og komplekse prestasjoner (Shanahan, Shanahan, \& Misischia, 2011; Wineburg, 1991). Siden lesere stadig endrer prosesseringsstrategi etter hvilken tekst de leser, kan høyttenkningsmetoder gi rike beskrivelser av komplekse kognitive og affektive prosesser og tilgang til resonnementene som sofistikert tenkning bygger på (Pressley \& Afflerbach, 1995, s. 4). Metoden beskrives som fleksibel (Hilden \& Pressley, 2011) og åpen fordi den lar seg tilpasse forskerens spørsmål. For å sikre mest mulig naturlig leseatferd hos deltakerne avsto vi fra å etterspørre konkrete strategier i instruksjonene (Hilden \& Pressley, 2011). Våre intervjuer varte fra 56-71 minutter og ble gjennomført av én eller flere deltakere i forskergruppen. Det semistrukturerte formatet gjorde at vi kunne stille oppfølgingsspørsmål underveis i alle tre fasene. Vi vektla å skape en ikke-stressende atmosfære i intervjusituasjonen slik at deltakerne følte seg trygge nok til å snakke om til dels vanskelige personlige erfaringer. Flere deltakere bemerket uoppfordret at det var både hyggelig og lærerikt å delta.

Vi tilrettela for samarbeidslesing hos deltakerne for å gienskape sosiale prosesser der felles meningsskaping kan skje når leserne kobler informasjon i teksten til sine bakgrunnskunnskaper (Suthers, 2006). Et slikt design kan gi informasjon om deltakeres tankerekker og refleksjoner i praktisk oppgaveløsning, samt gi tilgang til interaksjon mellom mennesker og tekster i lokal kontekst (Ericsson \& Simon, 1998), enten suksessivt eller samtidig (Kiili, Laurinen, Marttunen, \& Leu, 2012). Vektlegging av samarbeidslesing gjorde det dessuten mulig å skille mellom strategier for individuell meningsskaping på den ene siden, og sosiale strategier for kollektiv meningsskaping 
på den andre (Oxford \& Crookall, 1989). Intervjuene ble innsamlet med digitalt opptaksutstyr og transkribert.

\section{Analysestrategi}

Vi valgte en konstant komparativ tilnærming der enkelthendelser hele tiden sammenlignes med resten av datamaterialet for å konstruere mer overordnede kategorier (Corbin \& Strauss, 2008; Pressley \& Afflerbach, 1995). For eksempel identifiserte vi enkelthendelser der deltakerne delte levde erfaringer med opplæringslova eller andre lovtekster. Eksempler på slike levde erfaringer var opplevelser med klagesaker (skoleledere), forsøk på å kreve rett til spesialundervisning (skoleeiere) og dialog med skolen om barn med skoleutfordringer (foreldre). Disse ble kategorisert som levde erfaringer for hver lovtekst og deretter kombinert til samlekategorien levde erfaringer med lovtekster. Når det ikke lenger er mulig å identifisere eller kombinere kategorier, når analysen et metningspunkt. I høyttenkningsoppgaven var skillet mellom sosiale og tekstbaserte strategier for lovtekstforståelse fremtredende. Vårt metningspunkt ble nådd med identifiseringen av tre sentrale dimensjoner av juridisk literacy: 1) bruk av tekstbaserte og sosiale strategier for problemløsning, 2) tolkningsfellesskap og 3) $ø$ kende rettsliggjøring. I det følgende drøfter vi hva disse tre dimensjonene innebærer i vårt tilfelle.

\section{Resultater og diskusjon}

\section{Tekstbaserte og sosiale strategier for problemløsning}

Et første funn i studien er at lesere med høyere juridisk literacy primært anvender tekstbaserte strategier for å skape mening, mens lesere med lavere juridisk literacy primært anvender sosiale strategier. Skolelederne har et relativt velutviklet system for å informere om rettigheter og håndtere eventuelle konflikter. Rektor definerer kontaktlærerne som «førstelinjen» og påpeker at det bare er «enkelttilfeller» som kommer inn til skoleledelsen. Når tolkninger og beslutninger finner sted ved "førstelinjen" reduseres antallet saker som skoleledelsen må håndtere, noe som kan lede til større autonomi hos profesjonsutøverne og raskere saksbehandling. De rapporterer at samarbeid med jurister i kommunen om praktiske oppgaver har økt skoleledernes juridiske literacy, også for dem som ikke har formell juridisk utdanning fra før. Lederne påpeker at foreldregruppen er heterogen, og selv om de er enige $i$ at lovteksten bør være anvendbar av foreldre, vil det være umulig i praksis å skrive slik at alle foreldre forstår teksten.

Intervjuet med skolelederne viser likevel betydelige forskjeller i leseratferd: Skolelederne som mangler formell juridisk utdanning, bruker primært den digitale versjonen av lovteksten på lovdata.no og søker, skumleser eller skroller når de leser. En vanlig praksis er å søke etter allerede kjente stikkord, noe som forutsetter bakgrunnskunnskap om både lovverk og praksisfelt. De opplever teksten som velstrukturert og forståelig, men skiller mellom paragrafer som de kjenner godt og mindre brukte 


\section{H. Fjørtoft et al.}

paragrafer. Når de er usikre på tolkningen, følger de et etablert hierarki der rektor formelt tar saken videre med kommunens jurister, fylkesmannen og eventuelt direktorat og departement. Rektor, som har noe formell juridisk utdanning, foretrekker derimot å lese større deler av loven på papir:

Jeg bruker den ikke i digital utgave. Den ligger på pulten. Jeg kan finne på å sitte å lese utdrag av opplæringsloven (sic) i perioder for jeg føler for å ha en oversikt på enkelte områder. Fordi den er ganske omfattende. Og så er det av og til at du blir litt i tvil og leser heller store deler, men jeg bruker ikke så ofte noen spesielle søkeord.

Hans tilnærming er mindre preget av konkret problemløsning og mer av en generell interesse for juridiske spørsmål. Dette har for eksempel ført til at han har påvist feil i kommunens ansettelsespraksis, og at rutinene har blitt endret som følge av dette. Han har også tatt kontakt på direktoratsnivå i saker der han har vært uenig med fylkesmannens kontor om tolkningen av lovteksten. I rektors tilfelle får altså hans juridiske literacy positive ringvirkninger utover hans egen virksomhet. Dette er en konsekvens av hans evne til å navigere i juridiske tekster på selvstendig vis, og han uttrykker glede over å få "grave og holde på selv» fordi han lærer av dette arbeidet.

Blant foreldrene er det derimot primært de sosiale strategiene som blir fremhevet. De har kjennskap til Lovdata og vet at det kan finnes veiledninger, men beskriver dette som en «tung vei» å gå for å løse konflikter. Deres strategier for å løse juridiske spørsmål er derfor primært å ta kontakt med skolen, med jurister i foreldregruppen eller egen familie, eller å snakke med skoleeiers representanter. De uttrykker bekymring for å søke hjelp hos en potensiell motpart (skolen) og for kostnadene som advokathjelp innebærer. I vanskelige saker ville de ha brukt fylkesmannsapparatet, som de opplever som uhildet, og andre støttetjenester som interesseorganisasjoner og fagforeninger. Foreldrene kommenterer at det er en fordel å ha jurister blant familie og venner som de kan spørre om råd, men er bevisst at slike ressurser er ujevnt fordelt i befolkningen.

Generelt foretrekker altså mer kompetente lesere å orientere seg i tekster på egen hånd, noe som fører til at de kan løse problemer uten hjelp fra andre. Lesere med lavere juridisk literacy er derimot sjelden i stand til å lese lovtekstene alene, og de henvender seg derfor til andre for å få hjelp. Dette funnet er ikke overraskende, gitt at formell juridisk utdanning fokuserer på rettskildelære og evne til å bedømme ulike rettskilders gyldighet og vekt. Det antyder at høy juridisk literacy er kjennetegnet ved bruk av både tekstbaserte og sosiale strategier for meningsskaping.

\section{Tolkningsfellesskap}

Studiens andre hovedfunn er at aktørenes tolkningsfellesskap er en ressurs for mange i avklaringen av juridiske problemstillinger. Avklaring av tolkningsspørsmål utgjør for eksempel en sentral del av arbeidet med lovtekster i skoleeiernes hverdag. De kommuneansatte rådgiverne kontakter sin jurist dersom det er tvilsspørsmål. Juristen søker på direktoratets nettsider, og dersom dette ikke gir svar, kontakter hun Fylkesmannens kontor. Hun sier hun bruker mye tid på å lete i forarbeid, rundskriv 
og andre rettskilder. De kommuneansatte søker ofte etter navnet på en paragraf på lovdata.no fordi de har bakgrunnskunnskap om hva de ulike delene av loven inneholder. De opplever at søkefunksjonen på lovdata.no er mye bedre enn på Utdanningsdirektoratets nettsider fordi de kan søke etter flere stikkord samtidig. På Utdanningsdirektoratets sider er det også usikkert om nyeste versjon av dokumenter kommer lengst opp i trefflisten.

Bruken av tolkningsfellesskapet kan imidlertid være et tveegget sverd: Rektor forteller at han diskuterer saker med andre rektorer, men karakteriserer dette som et «minefelt» fordi noen skoleledere legger personlige tolkinger og referanserammer til grunn for lokale vedtak. Nye rektorer kan «faktisk bli vranglært» dersom de forholder seg for mye til sin egen yrkesgruppe og ikke følger tjenestevei i juridiske spørsmål, sier han. Samtidig skjer det også en stor andel «usynlig» tolkningsarbeid som ikke blir kommunisert til elever og foreldre: Enkelte begrep som brukes i forvaltningen, kan ha helt eller delvis overlappende betydninger, noe som utgiør et problem i kommunikasjonen mellom skole og foreldre. Rektor påpeker at det kan gå «inflasjon i ordbruken» når begreper som elevsamtale og kontaktsamtale anvendes synonymt. I slike sammenhenger forsøker skoleeier å skape mening og forståelse gjennom det rektoren kaller "avklarende skriv». Slike skriv er ment å avklare begrepsuklarheter.

Også her er det imidlertid nyanser: Jurister og andre med formell juridisk kompetanse må forholde seg til et juridisk fortolkningsfellesskap og til byråkratisk regulering av fortolkning. Kommunens rådgivere anvender først og fremst de skriftlige rettskildene for å avklare spørsmål. De kommenterer at de forsøker å etablere konsensus i tolkningsspørsmål, men at det er vanskelig å sikre at kommuner behandler saker likt. Når rettskildene ikke gir et svar, henvender de seg til Fylkesmannen eller til Utdanningsdirektoratet for å få tolkningsuttalelser. De opplever at ulike instanser tolker loven ulikt. Dette er en verdifull erfaring som skoleeiers representanter lærer av: «Når vi får det tilbake, så vet vi hvordan de tenker» (rådgiver uten juristutdanning). En rådgiver beskriver dette arbeidet som «runder», noe som antyder at tekstbaserte strategier komplementeres av sosiale strategier. Skoleeierne sier at de digitale dokumentene som er tilgjengelige på Utdanningsdirektoratets nettsider er vanskelige å søke i uten detaljert bakgrunnskunnskap, noe som kan forklare hvorfor de må søke støtte hos kolleger i visse tilfeller.

Skjønnsbegreper utløser særlig behov for tolkning og avklaring, noe som skaper spenninger mellom aktører og virksomheter. Skolelederne kommenterer at foreldre/ foresatte gjerne legger sine egne personlige fortolkninger av disse begrepene til grunn når de skal argumentere for barnas rettigheter. Foreldrene mener på sin side at det burde spesifiseres i lovverket hvem som har rett til å vurdere skjønnsspørsmål, og hva slags kompetanse disse personene skal ha. Det er også spenninger mellom aktørenes behov for skriftliggjøring. De kommuneansatte påpeker at noen paragrafer trolig tolkes strengere jo lengre opp man kommer i systemet, spesielt når det gjelder krav om skriftlig dokumentasjon. Mens skolens virksomhet kan være fundert på muntlig samhandling, krever forvaltningen på skoleeiernivå skriftliggjøring for å sikre tilstrekkelig 


\section{H. Fjørtoft et al.}

grunnlag i saksbehandlingen. Foreldrene etterlyser på sin side veiledninger med beskrivelser av hva som trengs for barn med spesielle behov. Forskjeller i forståelser og rutiner mellom disse tolkningsfellesskapene kan skape rom for både læring og konflikt. De ulike aktørene i systemet kan derfor sies å tilhøre ulike tolkningsfellesskap med ulik juridisk literacy.

\section{Økende rettsliggjøring}

Vårt tredje hovedfunn er knyttet til rettsliggiøring som samfunnsfenomen. Tilgang til lovtekster kan prinsipielt forstås som et demokratiserende virkemiddel, men studien viser også at økt tilgang kan føre til flere konflikter om tolkninger og skjønnsvurderinger i praksis. En mer rettighetsorientert og juridisk bevisst foreldregruppe har for eksempel ført til flere klager på lærernes karaktersetting. En skoleleder beskriver dette som en endring i foreldrerollen:

Det er en underlig utvikling. Jeg kan ikke tenke meg at mine foreldre i det hele tatt på 80-tallet tenkte på at de skulle klage på noen karakterer til meg. Og i hvert fall ikke slå opp i noen opplæringslov. Jeg tror det hadde vært helt utenkelig for dem.

Lovverkets tilgjengelighet har trolig resultert i denne endringen, og rektor ser dette som del av en generell utviklingstendens i samfunnet. Tidligere stilte ikke foreldre spørsmål ved skolens beslutninger. Økt bevissthet om klagerettigheter og mer konkurransebevisste elever og foreldre kan ha ført til at klagemengden øker i skolen. Skolelederne mener foreldrene og elever klager mer primært fordi de har rett til det rent juridisk, og ikke fordi de mener seg urettmessig behandlet. Det påvirker både skolens virksomhet og dynamikken i relasjonene mellom elevene, foreldrene og skolens ansatte: Mer kunnskap om jussen bak karakterer er nødvendig for å sikre god saksbehandling, men kan også føre til et høyere konfliktnivå og flere administrative oppgaver for skolen.

Foreldrene i vår studie er ikke representative for spesielt sårbare eller rettsfjerne grupper, men forteller likevel om såre minner fra konflikter med skolen. I intervjuet sier samtlige at de har hatt barn med særlige skoleutfordringer, og at de derfor har søkt kunnskap om rettighetene som opplæringslova regulerer. Bare én av foreldrene har lest lovteksten tidligere, og de påpeker at setningene er lange og tunge, og at de må leses mange ganger. Foreldrene opplever at lovteksten er lite spesifikk og derfor komplisert å lese fordi den skal dekke «alle eventualiteter». Ifølge foreldrene står det flere steder «bør» i stedet for «skal», noe som giør det vanskelig for foreldrene å forstå om det er snakk om anbefalinger eller krav. En forelder anser det formelle juridiske vedtaket sammen med betydelig egeninnsats som avgjørende for at hennes barn fikk støtte for lese- og skrivevansker i skolen:

Nå vet ikke jeg om det står i opplæringslova hva man giør med sånne konkrete ting, men jeg har også dysleksibarn. Men jeg fikk gjennom et system på barneskolen. Det tok fire år eller noe sånt. Selv om du har vedtak, så merker man at man kanskje skulle ha brukt loven. Man merker i hvert fall at man hele tiden må banke på dører igjen og si hallo, vi hadde et problem her. [...] Det er ikke automatikk $i$ at loven er 
lest eller veilederne er fulgt. Du må hele tiden banke på døra. Vi hadde jo en plan. Har planen slutta å virke, liksom?

Gjennom stadige henvendelser og påminnelser har forelderen sørget for systematisk oppfølging av elevens behov. Iherdig innsats har altså kompensert for forelderens manglende kunnskaper om rettigheter og manglende oppfølging fra skolens side. Dette er et eksempel på at rettsliggiøring kan virke positivt for regeletterlevelse i skolen: Når foreldrene har et formelt vedtak å vise til, kan det brukes som pressmiddel overfor skolens manglende oppfølging.

Foreldrene beskriver også hvordan det oppleves når skolen ikke tilrettelegger for elevene: En forelder forteller om hvordan manglende hjelp fra skole og støtteapparat skaper en følelse av avmakt:

Jeg har en sønn som har store lese- og skrivevansker, og som gikk til jevnlige tester på barneskolen. Men det ble aldri konstatert noe dysleksi. Og jeg mistenker at idet du får diagnosen, så har du plutselig noen rettigheter, og du kan kreve PC og du kan kreve flere ting som vil koste samfunnet noe. Så jeg har inntrykk av at skolen holdt igjen med å sette en diagnose. Men han var alltid på kritisk nivå på nasjonale prøver. Så det gikk bare alltid dårlig. Det har jo bare forfulgt han også nå på ungdomsskolen. Han strever jo hele tiden. [...] [J]eg fikk bare klar beskjed på barneskolen at nei, det var ikke noe. De halte det ut. Så var jeg kanskje ikke aktiv nok selv til å bruke lovverket og forfølge det. Det kjentes som en veldig tung vei å gå. Man utholdt situasjonen. Man bare tenker at jaja, det bedrer seg kanskje. Det blir sikkert bedre. Det blir sikkert en mann ut av dette mennesket her òg.

Forelderen opplever manglende dysleksidiagnose som en bevisst uthalingstaktikk fra skolens side. Erfaringen viser hvordan uklare signaler og manglende støtte i tidlige år kan hjemsøke familier også lenge etter, og hvordan slike erfaringer former forståelsen av skolens juridiske grunnlag og tilliten til skolesystemets evne til å håndtere elevers utfordringer på en rettferdig måte. Forelderen har imidlertid ikke valgt å løse dette problemet ved å gå juridisk vei, noe som igjen fører til dårlig samvittighet for egen foreldreinnsats.

Et spesielt problem i skolesammenheng er at skoleledere skal gi råd til foreldre om juridiske rettigheter samtidig som de blir motparter i en eventuell konflikt. Foreldrene gir uttrykk for at lovtekstens vaghet eller flertydighet kan utnyttes for å spare penger i skolesystemet, og at dette kan få negative konsekvenser for enkelte elevgrupper. Skjønnsvurderinger har stort tolkningsrom og kan utnyttes av skoleeiere for å "slippe å bruke mye penger» på spesialundervisning, som en forelder uttrykker det. Utsagnet vitner om en tvilende holdning til oppfyllelsen av rettigheter for elever med spesielle behov, og knyttes spesifikt til paragrafer som åpner for skjønnsutøvelse. Lovteksten inneholder tilrådinger og ikke krav, og deltakerne spør seg om dette er et bevisst grep fordi det er myndighetene selv som skal oppfylle rettighetene i loven.

Foreldrene etterlyser mer juridisk kompetanse i skolen hos både undervisningspersonell og hos rådgivere som skal sørge for at elevers rettigheter etterleves. Samtidig er 


\section{H. Fjørtoft et al.}

de frustrerte over at ressursene er begrensede, samt at ulike grupper prioriteres over andre, som for eksempel når det kommer øremerkede midler til minoritetsspråklige elever uten at elever med lese- og skrivevansker får den støtte de har krav på. Loven angir heller ikke hvem som skal foreta vurderinger eller nøyaktig hvor lang tid skoler kan bruke for å behandle mobbesaker. En forelder mener å se en tendens til "amerikanisering av bruk av lovverket» noe som i denne sammenheng kan tolkes som en negativ form for rettsliggiøring.

Foreldrenes erfaringer med rettsliggiøring er derfor tvetydige: Tilgang til lovtekstene fremmer rettighetsbevisstheten hos foreldre og kan sikre at elever med spesielle behov mottar den hjelp de behøver, men bidrar samtidig til flere klager og konflikter mellom de ulike aktørene.

\section{Implikasjoner av studien}

Vanlige borgere legitimerer statsmakten gjennom demokratiet, og de skal også kunne orientere seg i de rammer og reguleringer som statsmakten setter for deres livsutfoldelse. God saksbehandling i grunnopplæringen er et premiss for å sikre at elevenes rettigheter blir overholdt. Dette er spesielt viktig for de elever og foreldre som kan karakteriseres som rettsfjerne individer. Studier av ikke-juristers lovtekstlesing og rettsanvendelse kan derfor både kaste lys på problematiske saksområder og bidra til økt bevissthet eller forbedret praksis. Bevissthet om juridisk literacy som et individuelt og sosialt fenomen kan for eksempel bidra til en mer nyansert forståelse for rettsanvendelse i skolen. Graden av juridisk literacy hos den enkelte påvirker hvilke strategier den enkelte har til rådighet i skjønnsutøvelse og konflikthåndtering. Dette funnet bekrefter det overordnede skillet mellom allmenhet og fagpersonaler som Justis- og politidepartementet (2000) skisserer.

Studien viser imidlertid også at allmenheten er en svært variert kategori. Det kan være problematisk for profesjonsutøvere å søke tolkningsstøtte i ikke-juridiske profesjonsfellesskap; høy pedagogisk kompetanse garanterer ikke god rettsanvendelse i praksis. Videre er juridiske støttetjenester i kommunene gjerne lokalisert hos skoleledernes arbeidsgivere, noe som betyr at skoleeier både skal veilede og føre ettersyn med skoleledernes skjønnsutøvelse og rettsanvendelse. Det kan føre til rollekonflikter mellom skoleleder og skoleeier. Dette indikerer at arbeidet med å kultivere tolkningsfellesskap hos ikke-jurister bør vies økt oppmerksomhet slik at skolen kan unngå misforståelser og uheldige situasjoner i møte med elever og foreldre. Welstad (2011) foreslår å følge prinsippet om merrettssikkerhet i slike tilfeller: Skolen kan veilede elevene i saker som berører dem slik at deres interesser kan ivaretas best mulig, selv når en avgjørelse ikke kan defineres som enkeltvedtak.

Anvendelse av lovtekster i det daglige, enten det gjelder ukompliserte samlebåndssaker eller mer komplekse skjønnsvurderinger, bør bygge på kunnskap om både pedagogiske og juridiske problemstillinger, samt forståelse for de ulike erfaringene ikke-jurister kan ha med lovverket og forvaltningen. For eksempel bør skolesystemet ta høyde for at 
tekstbaserte strategier fungerer best for lesere som allerede har en viss formell juridisk kompetanse, og at de fleste andre er avhengige av å bruke sosiale strategier gjennom formelle og uformelle veilednings- og rådgivningsfunksjoner. Hvis ikke-juristers juridiske literacy utvikles gjennom møter med det offentliges saksbehandling, bør saksbehandlere på skole- og skoleeiernivå etterstrebe å sette seg inn i de personlige erfaringer som elever og foreldre kan ha. Deres forventninger til skolens rettsanvendelse kan variere sterkt, og dersom tilliten til skolen som rettsanvender skal opprettholdes, er det viktig å forstå de levde erfaringer som har formet forståelsen av skolejuss. Ansatte i forvaltningen bør være spesielt sensitive for borgernes negative erfaringer med juss og sørge for at saksbehandling og oppfyllelse av rettigheter kommuniseres med omhu.

\section{Bibliografi}

Andenæs, K. \& Møller, J. (Red.). (2016). Retten i skolen: mellom pedagogikk, juss og politikk. Oslo: Universitetsforlaget.

Andenæs, K. \& Olsen, L. O. (1990). Sosial rett II. Sosialrettens oppgaver mot år 2000. Oslo: Tano.

Barnes, J. (2006). The Continuing Debate About «Plain Language» Legislation: A Law Reform Conundrum. Statute Law Review, 27(2), 83-132. https://doi.org/10.1093/slr/hml004

Bazerman, C. (1997). Discursively Structured Activities. Mind, Culture, and Activity, 4(4), 296-308. https://doi. org/10.1207/s15327884mca0404_6

Beach, R. (2000). Critical issues: Reading and responding to literature at the level of activity. Fournal of Literacy Research, 32(2), 237-251. https://doi.org/10.1080/10862960009548075

Bell, D. \& Pether, P. (1998). Re/Writing Skills Training In Law Schools — Legal Literacy Revisited. Legal Education Review, 9(113). Hentet fra http://www.ler.edu.au/1998_2_fullpapers_new.htm

Bråten, I. \& Strømsø, H. I. (2003). A longitudinal think-aloud study of spontaneous strategic processing during the reading of multiple expository texts - Springer. Reading and Writing, 16(3). (Hentet fra): http://ink. springer.com/article/10.1023/A:1022895207490

Corbin, J. M. \& Strauss, A. L. (2008). Basics of qualitative research: techniques and procedures for developing grounded theory. (3rd ed). Los Angeles, Calif: Sage Publications, Inc.

Cover, R. M. (1992). Nomos and Narrative. I M. Minow, M. Ryan \& A. Sarat (Red.), Narrative, violence, and the law: the essays of Robert Cover. Ann Arbor: University of Michigan Press.

Direktoratet for forvaltning og IKT. (2017). Klart lovspråk. Hentet fra https://www.difi.no/fagomrader-og-tjenester/ klart-sprak-og-brukerinvolvering/klart-lovsprak

Eckhoff, T. E. \& Helgesen, J. E. (2001). Rettskildelcere. (5. utg). Oslo: Universitetsforlaget.

Ericsson, K. A. \& Simon, H. A. (1998). How to Study Thinking in Everyday Life: Contrasting ThinkAloud Protocols With Descriptions and Explanations of Thinking. Mind, Culture, and Activity, 5(3), 178-186. https://doi.org/10.1207/s15327884mca0503_3

Evans, B. M., Kairam, S. \& Pirolli, P. (2010). Do your friends make you smarter?: An analysis of social strategies in online information seeking. Information Processing E Management. 46(6), 679-692. https://doi. org/10.1016/j.ipm.2009.12.001

Ewick, P. \& Silbey, S. S. (1998). The common place of law: stories from everyday life. Chicago: University of Chicago Press.

Gee, J. P. (2012). Social linguistics and literacies: ideology in discourses. (4th ed). Abingdon, Oxon; New York: Routledge.

Geisler, C. (1994). Academic literacy and the nature of expertise: reading, writing, and knowing in academic philosophy. Hillsdale, N.J: Lawrence Erlbaum Associates.

Halstensgaard, C. D. (2016). Hvordan kommunisere gjennom skreven tekst? En tekstvitenskapelig undersøkelse av tre brevmaler om scerksilt språkopplaring $i$ Osloskolen (Masteroppgave). Universitet i Oslo, Oslo. Hentet fra https://www.duo.uio.no/handle/10852/55087?show=full

Herlofsen, C., \& Nilsen, S. (2016). Spesialundervisning i spenningsfeltet mellom juridisk regelverk og lokal praksis. I K. Andenæs \& J. Møller (Red.), Retten i skolen: mellom pedagogikk, juss og politikk. Oslo: Universitetsforlaget. 


\section{H. Fjørtoft et al.}

Gunnarsson, B. L. (1982). Lagtexters begriplighet. Stockholm: LiberFörl.

Hilden, K. \& Pressley, M. (2011). Verbal Protocols of Reading. I N. K. Duke \& M. H. Mallette (Red.), Literacy research methodologies (2nd ed, s. 427-440). New York: Guilford Press.

Justis- og politidepartementet. (2000). Lovteknikk og lovforberedelse. Veiledning om lov- og forskriftsarbeid. Justisog politidepartementet. Hentet fra https:/www.regjeringen.no/no/dokumenter/veiledning-om-lov--og forskriftsarbeid/id87536/

Kiili, C., Laurinen, L., Marttunen, M. \& Leu, D. J. (2012). Working on Understanding During Collaborative Online Reading. Fournal of Literacy Research, 44(4), 448-483. https://doi.org/10.1177/1086296X12457166

Kolflaath, E. (2004). Flertydige lovtekster. Lov og Rett, 43(07-08). Hentet fra http://www.idunn.no/ts/ lor/2004/07-08/flertydige_lovtekster

Leo, U. (2010). Rektorer bör och rektorer gör: en rättssociologisk studie om att identifiera, analysera och förstå professionella normer. Sociologiska institutionen, Lunds universitet, Lund.

Luff, P., Heath, C. \& Hindmarsh, J. (2000). Introduction. I P. Luff, J. Hindmarsh, \& C. Heath (Red.), Workplace studies: recovering work practice and informing system design. Cambridge, UK; New York, NY, USA: Cambridge University Press.

Lundeberg, I. R. (2009). Sannhetsvitnet. Tidsskrift for Rettsvitenskap, 122(4-5), 611-645.

Nord, A. (2011). Att göra någon annans text tydlig (No. TeFa nr 48.). Uppsala: FUMS, Institutionen för nordiska språk, Uppsala universitet. Hentet fra http://gup.ub.gu.se/publication/151815-att-gora-nagon-annans-text-tydlig

NOU 2003: 19 Makt og demokrati. Sluttrapport fra Makt-og demokratiutredningen. (udatert). Hentet fra https:// www.regjeringen.no/no/dokumenter/nou-2003019/id118893/?ch=1\&q=

Oxford, R. \& Crookall, D. (1989). Research on Language Learning Strategies: Methods, Findings, and Instructional Issues. The Modern Language fournal, 73(4), 404-419. https://doi.org/10.1111/j.1540-4781.1989. tb05321.x

Papendorf, K. (2012). Rett for alle? Rettsliggjøring og rettsfjerne personers mulighet til å mobilisere retten. Oslo: Novus forlag.

Pressley, M. \& Afflerbach, P. (1995). Verbal protocols of reading: the nature of constructively responsive reading. Hillsdale, N.J: Lawrence Erlbaum Associates.

Sandvik, L. V., Engvik, G., Buland, T., Fjørtoft, H., Langseth, I., Aaslid, B. E. \& Mordal, S. (2012). Vurdering i skolen. Intensjoner og forståelser. Delrapport 1 fra prosjektet Forskning på individuell vurdering $i$ skolen (FIVIS). Trondheim: NTNU/SINTEF.

Schimmel, D. \& Militello, M. 2007). Harvard Educational Review - Legal Literacy for Teachers: A Neglected Responsibility. . Harvard Educational Review, 77(3), 257-284.

Shanahan, C., Shanahan, T. \& Misischia, C. (2011). Analysis of Expert Readers in Three Disciplines: History, Mathematics, and Chemistry. Fournal of Literacy Research: A Publication of the Literacy Research Association, 43(4), 393-429. https://doi.org/10.1177/1086296X11424071

Strømsø, H. (2003). Hvordan arbeider jusstudenter med juridiske fagtekster? Retfærd. Nordisk Furidisk Tidsskrift, 26(4), 3-13.

Suthers, D. D. (2006). Technology affordances for intersubjective meaning making: A research agenda for CSCL. International fournal of Computer-Supported Collaborative Learning, 1(3), 315-337. https://doi. org/10.1007/s11412-006-9660-y

Thagaard, T. (2013). Systematikk og innlevelse: en innføring $i$ kvalitativ metode. Bergen: Fagbokforlaget.

Vatn, G. Å., Eriksen, P. F., \& Fjørtoft, H. (Red.). (2015). Klart lovspråk? Furidiske tekster $i$ et virksomhetsperspektiv. Trondheim: NTNU. Hentet fra http://www.sprakradet.no/Klarsprak/Diverse/Toppmeny5/Aktuelt/ Ny-undersokelse-fra-NTNU-Er-lovene-forstaelige/

Welstad, T. (2011). Skoleledere som rettsanvendere. I J. Møller \& E. Ottesen (Red.), Rektor som leder og sjef: styring, ledelse og kunnskapsutvikling i skolen. (s. 119-146).

White, J. B. (1982). The Invisible Discourse of the Law: Reflections on Legal Literacy and General Education. Michigan Quarterly Review, 21(3). Hentet fra http://hdl.handle.net/2027/spo.act2080.0021.003:07

Wineburg, S. S. (1991). On the Reading of Historical Texts: Notes on the Breach Between School and Academy. American Educational Research fournal, 28(3), 495-519. 